Heiko U. Wittmer · Anthony R. E. Sinclair

Bruce N. McLellan

\title{
The role of predation in the decline and extirpation of woodland caribou
}

Received: 22 July 2004 / Accepted: 16 February 2005/Published online: 11 May 2005

(C) Springer-Verlag 2005

\begin{abstract}
To select appropriate recovery strategies for endangered populations, we must understand the dynamics of small populations and distinguish between the possible causes that drive such populations to low numbers. It has been suggested that the pattern of population decline may be inversely density-dependent with population growth rates decreasing as populations become very small; however, empirical evidence of such accelerated declines at low densities is rare. Here we analyzed the pattern of decline of a threatened population of woodland caribou (Rangifer tarandus caribou) in British Columbia, Canada. Using information on the instantaneous rate of increase relative to caribou density in suitable winter foraging habitat, as well as on pregnancy rates and on causes and temporal distribution of mortalities from a sample of 349 radiocollared animals from 15 subpopulations, we tested 3 hypothesized causes of decline: (a) food regulation caused by loss of suitable winter foraging habitat, (b) predation-sensitive foraging caused by loss of suitable winter foraging habitat and (c)
\end{abstract}

Communicated by John Fryxell

H. U. Wittmer $(\bowtie)$

Agroecology, Faculty of Agricultural Sciences,

University of British Columbia, 2357 Main Mall,

Vancouver, BC, V6T 1Z4, Canada

A. R. E. Sinclair

Centre for Biodiversity Research, University of British Columbia,

6270 University Boulevard,

Vancouver, BC, V6T 1Z4, Canada

B. N. McLellan

Ministry of Forests, Research Branch,

PO Box 9158, RPO \#3, Revelstoke,

BC, V0E 3K0, Canada

Present address: H. U. Wittmer

Department of Environmental Science,

Policy and Management,

University of California, Berkeley,

CA 94720-3110, USA

E-mail: wittmer@xtra.co.nz predation with caribou being secondary prey. Population sizes of caribou subpopulations ranged from $<5$ to $>500$ individuals. Our results showed that the rates of increase of these subpopulations varied from -0.1871 to 0.0496 with smaller subpopulations declining faster than larger subpopulations. Rates of increase were positively related to the density of caribou in suitable winter foraging habitat. Pregnancy rates averaged 92.4\% \pm 2.24 and did not differ among subpopulations. In addition, we found predation to be the primary cause of mortality in 11 of 13 subpopulations with known causes of mortality and predation predominantly occurred during summer. These results are consistent with predictions that caribou subpopulations are declining as a consequence of increased predation. Recovery of these woodland caribou will thus require a multispecies perspective and an appreciation for the influence of inverse density dependence on population trajectories.

Keywords Allee effect - Apparent competition Inverse density dependence $\cdot$ Rangifer tarandus caribou $\cdot$ Population dynamics

\section{Introduction}

Large herbivores are sometimes regulated by extrinsic factors such as food supply and the relationship between the instantaneous rate of increase $(r)$ and population density can be nonlinear (convex) with $r$ declining as population size increases (Sinclair 1989; Mduma et al. 1999; Sibly and Hone 2002; Sinclair and Krebs 2002). In addition, density-independent factors such as weather fluctuations, can also affect population growth rates (Post and Stenseth 1998). Because not all age and sex classes respond equally to variations in population density or weather, it is difficult to distinguish clearly between density dependence and density independence (Milner et al. 1999; Coulson et al. 2001). Therefore, in the absence of predators, population dynamics of large 
herbivores are often determined by the interaction of density-dependent competition for resources and environmental stochasticity (Sæther 1997; Gaillard et al. 2000).

Population declines of many large herbivores due to landscape modification and overexploitation have recently prompted increased attention on the effect of rarity on population dynamics. Due to factors such as inbreeding, demographic stochasticity, and loss of cooperative interactions with conspecifics, the per capita rate of increase may decrease as populations reach small sizes or low densities (Courchamp et al. 1999a; Stephens and Sutherland 1999). These factors produce an inverse density-dependent decline or Allee effect (Allee et al. 1949), and populations may decline to extinction below a threshold density (Dennis 2002). Despite the important consequences of inverse density dependence for the conservation and recovery of endangered populations, there are few examples of accelerated population declines at low density largely because of the inherent difficulties of studying small populations (Sutherland and Norris 2002).

Studies of the effects of density dependence and density independence on population growth are commonly based on time series analyses within single populations. Not only is it difficult to attribute cause and effect with time series analyses (Bjørnstad and Grenfell 2001), but the effects of population density are often masked by time lags in density responses or confounding density-independent factors (Shenk et al. 1998). Caughley (1994) proposed the use of hypotheticodeductive methods within an experimental design to distinguish between potential causes of decline. The application of a classical experimental design to study an endangered species, however, is often impractical and sometimes unethical in natural conditions (Courchamp et al. 1999a). To overcome this limitation, Sinclair (1991) suggested taking advantage of natural experiments that provide variation in population densities and the external factors influencing population dynamics.

The distribution of sedentary woodland caribou (Rangifer tarandus caribou) has contracted across their range in North America (Bergerud 1974, 1996). Because of declining population trends and increasing population fragmentation, woodland caribou are now considered threatened over large areas of their distribution by the Committee on the Status of Endangered Wildlife in Canada (COSEWIC 2002). The densities of remaining woodland caribou populations are low and typically vary between $0.01-0.04 \mathrm{~km}^{-2}$ in boreal habitats and $0.04-0.12 \mathrm{~km}^{-2}$ in mountainous habitats (COSEWIC 2002). Food limitation during winter and/or summer, adverse climate, and increased predation facilitated by accelerated forest harvesting and associated increases in ungulate species and predators, have all been proposed to affect population dynamics of woodland caribou in North America (Bergerud 1996; Rettie and Messier 1998). However, to select appropriate recovery strategies for endangered populations, we need to distinguish between the possible causes that drive populations to low numbers or even to extinction.

Here we use data sampled over the entire distribution of a threatened woodland caribou population in the interior wet-belt of British Columbia (COSEWIC 2002) and take advantage of differences in population densities and external factors influencing these densities. Our study objectives are to determine rates and causes of the decline of woodland caribou in the area using an interrather than an intra-population approach. Specifically, using information on rates of decline relative to population density per area of suitable winter foraging habitat, as well as on pregnancy rates and on causes and temporal distribution of mortalities, we aim to distinguish between the following three potential causes of decline (Table 1).

\section{(a) Food regulation due to habitat loss}

As food availability increases, population growth rate generally increases to a maximum for the species (Caughley 1976; Sibly and Hone 2002). Loss of suitable habitat may precipitate population declines if increased population densities in the remaining habitat result in increased mortality or reduced reproduction (Sutherland 1996). As a result of the unusually high snow accumulation $(>2 \mathrm{~m})$ in the interior wet-belt of British Columbia during winter, woodland caribou in the area depend almost exclusively on long-strand arboreal lichen (Bryoria spp. and Alectoria sarmentosa) (Rominger and Oldemeyer 1989; Rominger et al. 1996; Terry et al. 2000). Arboreal lichen is more abundant in old forest stands, thus, these obligate arboreal lichen feeding woodland caribou in the interior wet-belt of British Columbia are closely associated with late successional forests (i.e. > 140 years) (Apps et al. 2001). Logging
Table 1 Predictions of instantaneous rate of increase $(r)$, pregnancy rates and cause and temporal distribution of mortalities according to three hypotheses proposed to explain the decline of arboreal lichen feeding woodland caribou in British Columbia (a) food regulation caused by loss of suitable winter foraging habitat, (b) predation-sensitive foraging (PSF) caused by loss of suitable winter foraging habitat and (c) predation with caribou being secondary prey

\begin{tabular}{lllll}
\hline Cause of decline & Instantaneous rate of increase $(r)$ & Pregnancy rates & Cause of mortality & Mortality season \\
\hline Food & Highest at low densities (density-dependent) & Low at high densities & Malnutrition & Winter \\
PSF & Highest at low densities (density-dependent) & Low at high densities & Predation & Winter \\
Predation & Lowest at low densities (inverse density-dependent) & High (density-independent) & Predation & Summer \\
\hline
\end{tabular}


these forests might have led to increased caribou densities in remaining patches of old forest stands, reducing per capita food availability during winter to below a critical threshold. Following the ratio-dependent theory of consumer-resource interactions proposed by Arditi and Ginzburg (1989), we investigated population rate of increase relative to the ratio of population size per area of suitable winter foraging habitat (forest $>140$ years). If the declines of caribou subpopulations were caused by a per capita decrease in food availability, we expected rates of increase to be highest at low population densities measured by the number of animals per area of forests $>140$ years of age (Fig. 1). In addition, if food availability was causing population declines, then we would expect lower pregnancy rates at high population densities and the majority of animals to die as a consequence of malnutrition during winter, when food resources are more limited.

(b) Predation-sensitive foraging due to habitat loss

Predation and food can jointly limit population size. Caribou could respond to declining amounts of suitable winter foraging habitat by increasing the time that they spend foraging in riskier habitat, and thus increase their vulnerability to predators. A decrease in suitable habitat could also lead to malnutrition and thus reduced ability to avoid being killed by predators. Predation-sensitive foraging affects the population dynamics of prey because predators often kill animals that are in poor condition and foraging in riskier habitats which they use due to declining food supplies in safer habitats (Sinclair and Arcese 1995). The predation-sensitive foraging (PSF) hypothesis differs from the food regulation hypothesis in that the decline of caribou is still caused by habitat loss (food depletion causes a change in foraging behaviour), but mortality is primarily due to predators. Thus, if the decline of caribou is a consequence of predation-sensitive foraging, we expected rates of increase to be highest at low population densities, again measured as the

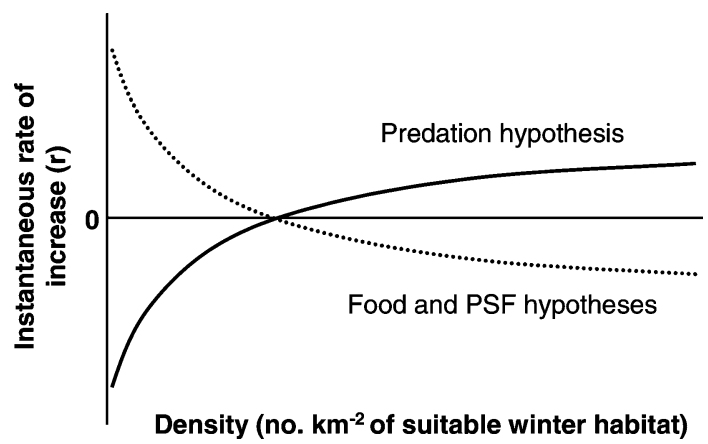

Fig. 1 Predicted relationship between instantaneous rate of increase $(r)$ and density per area of suitable winter foraging habitat for food regulation and predation-sensitive foraging (PSF) hypotheses (broken line) and predation hypothesis (solid line): modified from Caughley and Sinclair 1994; Sinclair et al. 1998 number of caribou per area of forests $>140$ years (Fig. 1). In addition, we expected lower pregnancy rates at high population densities. In contrast to the food regulation hypothesis, we expected the majority of animals to die from predation and caribou should be killed by predators during winter when food resources are more limited.

\section{(c) Predation}

In a system where 2 or more prey populations share a common group of predators (that are food limited), changes in the density of 1 prey population can lead to the decline or the extinction of the other prey population even in the absence of resource competition. This indirect interaction between prey populations is referred to as "apparent competition" (Holt 1977; 1984). Apparent competition occurs when predators asymmetrically impact populations of prey species. If the numerical response of a predator is dependent on the abundance of one species that is increasing, the primary prey, it can depress the population of another species, the secondary prey (superficially resembling competition between the prey). The predation on secondary prey can be incidental. The proportional effect of such incidental mortality is inversely density dependent, i.e. mortality increases proportionately as numbers of prey decline (Sinclair et al. 1998). Coexistence of prey populations may only be possible where there are effective spatial or temporal refuges for the prey populations that counteract the inverse density dependence (Holt and Lawton 1994). An example of such a process is the change in two endemic carnivores in the Channel Islands of California following the colonization of a top predator (Roemer et al. 2002). It has been suggested that the observed changes in British Columbia of an increasing ungulate prey population such as moose (Alces alces) since the early 1900s (Spalding 1990), and increasing predator populations such as wolves (Canis lupus) that are dependent on these prey, lead to the hypothesis of apparent competition, namely that caribou, as secondary prey, are decreasing from predation (Bergerud and Elliot 1986; Seip 1992).

The susceptibility of woodland caribou to predation has led to patterns of habitat use that separate them from other ungulates in the same geographic area (Bergerud and Page 1987; Seip 1992). Changes in the forest age structure may compromise the ability of caribou to avoid other prey species and their predators because young forests support higher densities of alternate ungulate species such as moose (Rempel et al. 1997) that in turn support higher predator densities leading to increased predation on caribou (Bergerud and Elliot 1986; Seip 1992). Thus, if the decline of woodland caribou is caused by increased levels of predation where caribou are preyed upon secondarily by predators that depend on other primary prey, we predicted rates of increase of caribou to be lowest at low population 
densities per area of forests $>140$ years (Fig. 1). Furthermore, in the absence of food limitation, we expected pregnancy rates to be high and constant among subpopulations even at high caribou densities. In addition, we predicted caribou to die primarily due to predation with the majority of predation occurring during summer when the distribution of woodland caribou in the area overlaps that of alternate prey species and their predators (Seip 1992).

\section{Materials and methods}

\section{Study area}

Arboreal lichen feeding woodland caribou, the southernmost remaining woodland caribou in western North America, are found in southeastern British Columbia and extreme northern Idaho from the international border at $49^{\circ} \mathrm{N}$ latitude to northeast of Prince George at about $55^{\circ} \mathrm{N}$ latitude (Fig. 2). In 2002, the estimated 1,850 of these caribou were fragmented into 18 distinct subpopulations (Wittmer 2004). Their total distribution encompasses an estimated $29,749 \mathrm{~km}^{2}$ of mostly mountainous terrain with elevation varying from approximately $400 \mathrm{~m}$ to $>3,500 \mathrm{~m}$. The distribution of arboreal lichen feeding woodland caribou is closely associated with the interior wet-belt ecosystem where high annual precipitation and cool climate results in deep snowpacks and infrequent natural fires (Meidinger and Pojar 1991).

Vegetative communities in the study area are primarily divided into the Interior Cedar-Hemlock (ICH) and Engelmann Spruce-Subalpine Fir (ESSF) biogeo-

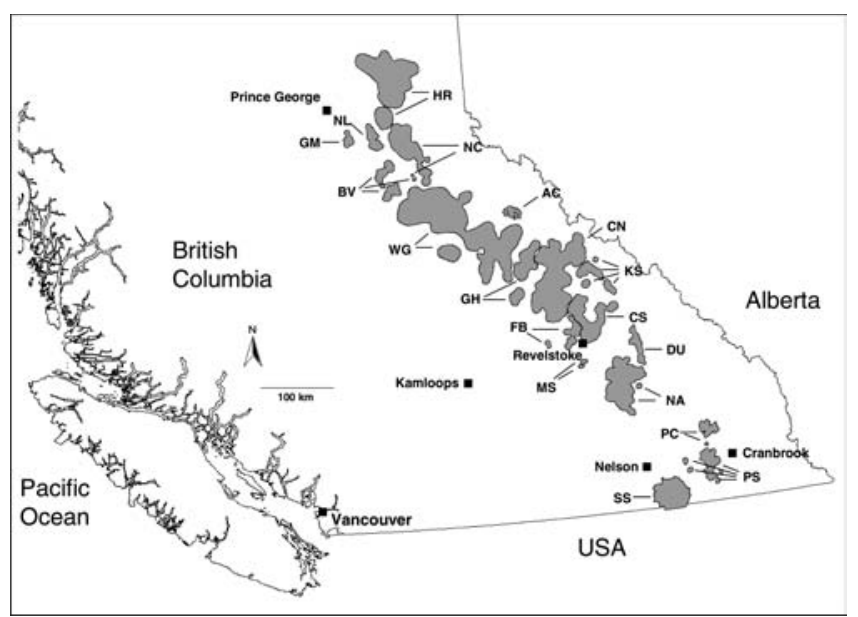

Fig. 2 Current distribution of identified subpopulations of arboreal lichen feeding woodland caribou (Rangifer tarandus caribou) in British Columbia: South Selkirks (SS), Purcells-South (PS), Purcells-Central $(P C)$, Nakusp $(N A)$, Duncan $(D U)$, MonasheeSouth $(M S)$, Columbia-South $(C S)$, Frisby-Boulder $(F B)$, Columbia-North $(C N)$, Kinbasket-South $(K S)$, Groundhog $(G H)$, Wells Gray $(W G)$, Allan Creek $(A C)$, Barkerville $(B V)$, North Cariboo Mountain $(N C)$, George Mountain $(G M)$, Narrow Lake $(N L)$, Hart Ranges $(H R)$ (from Wittmer 2004) climatic zones (Meidinger and Pojar 1991). Western redcedar (Thuja plicata) and western hemlock (Tsuga heterophylla) dominate climax ICH forests at lower elevation while Engelmann spruce (Picea engelmannii) and subalpine fir (Abies lasiocarpa) dominate climax ESSF forests at mid-elevation. Due to the wet conditions, forests are often hundreds of years old (Meidinger and Pojar 1991). Above the forested ecosystems is the alpine tundra (AT) biogeoclimatic zone that is sometimes vegetated by shrubs, grasses, sedges, forbs and lichens but also includes bare soil, rock and glaciers. Forestry is the dominant land-use activity across the range of arboreal lichen feeding woodland caribou and clear-cutting and replanting is the most common silvicultural system used.

Moose are found throughout the range of arboreal lichen feeding woodland caribou but are more abundant in northern and central parts of the study area (Spalding 1990; Shackleton 1999). Although moose have not been censused across our entire study area, their numbers in a $1,050-\mathrm{km}^{2}$ area in the centre of caribou distribution more than doubled between 1992 and 2002 reaching average winter densities of $1.58 \mathrm{~km}^{-2}$ (G.K. Poole and R. Serrouya, unpublished report). Mountain goats (Oreamnos americanus) and mule deer (Odocoileus hemionus) are also found throughout the study area but their abundance varies greatly with climate and topography. White-tailed deer $(O$. virginianus) and elk (Cervus elaphus), are abundant in southern areas and their distribution has been expanding (Shackleton 1999). Common predators across the distribution of arboreal lichen feeding woodland caribou include grizzly bear (Ursus arctos), black bear (U. americanus), and wolverine (Gulo gulo). Wolf populations have rapidly expanded into central and southern parts of the study area during the 1980s (Hayes and Gunson 1995) but are still more abundant in the north while cougar (Puma concolor) are more abundant in the south.

\section{Animal capture and pregnancy rates}

Between 1984 and 2002, 349 adult caribou (301 f, 48 m) were captured in open subalpine habitat during late winter using a net-gun fired from a helicopter. Because a high proportion of the population is visible and available for capture at this time of the year, over time, animals were collared in a geographic distribution that approximated the entire estimated distribution of arboreal lichen feeding woodland caribou in British Columbia. Captured caribou were fitted with either conventional very high frequency (VHF) mortality-motion sensitive radiocollars or global positioning system (GPS) collars that included VHF signals and mortalitymotion sensors.

Over a portion of the whole sampling period, blood samples were collected during capture from 134 adult female caribou ( $>2.5$ years) over different years and subpopulations. Pregnancy rates were estimated from 
serum progesterone levels. We used a threshold progesterone value of $7 \mathrm{nmol} \mathrm{1}^{-1}$ to assess pregnancy status of caribou. Ropstad et al. (1999) have shown that plasma progesterone lower than $7 \mathrm{nmol} 1^{-1}$ rarely occur in pregnant reindeer (Rangifer tarandus tarandus). In addition, the accuracy in assessing pregnancy in our study was increased because we took blood samples in late March and early April when oestrus cycling of nonpregnant caribou is unlikely to occur. We used loglikelihood ratios to determine if pregnancy rates differed among subpopulations (Zar 1999).

Causes and temporal distribution of mortalities

The location and status of collared animals was confirmed from fixed-wing aircraft 2-4 times each month. When the signal from a motion-sensitive radiocollar indicated that a caribou was dead, the site was investigated as soon as possible. The cause of mortality was determined from evidence at the site and, when possible, from a necropsy that included a measure of bone marrow, visceral, and rump fat deposits. Predation was suggested when there was evidence of bleeding, a struggle, or bite injuries. These cases were usually clear when there was snow on the ground, but less so during other times. Non-predation deaths were divided into accidents (i.e. avalanches, birthing, falls), malnutrition, human caused, or unknown. In many cases it was difficult to determine the cause of death and we conservatively classified the cause as unknown.

Summer (11 June-21 October), early winter (22 October-11 January), late winter (12 January-23 April), and spring (24 April-20 May) seasons, into which mortalities were grouped, were based on average dates of elevational movements of caribou in the Columbia Mountains where these movements are more distinctive than in other areas (Apps et al. 2001). The calving season was when radiocollared female caribou in the Columbia Mountains were first (21 May) and last (10 June) observed with new calves. We tested for seasonal differences in probability of dying adjusted for season length for all natural mortality causes (i.e. excluding human caused mortalities) and predator caused mortalities only using log-likelihood ratios.

\section{Population sizes and trends}

Subpopulations were surveyed from helicopters at irregular intervals in March or early April when arboreal lichen feeding woodland caribou are in open, high elevation habitats. Population estimates and $95 \%$ confidence limits were derived from the census results using the joint hypergeometric maximum likelihood estimator (JHE) (Bartmann et al. 1987) in the NOREMARK computer program (White 1996). In cases where the lower $95 \%$ confidence limit was below the actual number of caribou seen during census flights, we used the census result as the lower confidence limit. Some subpopulations were small and thus there were too few radiocollared animals to estimate population size using the proportion marked that were observed. Thus, in the absence of marked individuals in a subpopulation we applied a correction factor of $84.57 \%$ based on the sightability of 307 of a total of 363 marked animals during population censuses pooled over all years and subpopulations. We then calculated the instantaneous rate of increase $(r)$ for each subpopulation, as

$r=\frac{\ln N_{2002}-\ln N_{0}}{t}$

where $N_{2002}$ is the number of caribou in year 2002, $N_{0}$ is the number of caribou in the initial year, and $t$ is the number of years between $N_{0}$ and $N_{2002}$ (Caughley and Sinclair 1994). Because subpopulations were delineated a posteriori based on telemetry locations of radiocollared animals (Wittmer 2004), reliable estimates of population trends were limited to the period between 1992 and 2002.

Population densities relative to habitat index

Forest age variables were extracted from 1:20,000 digital inventory planning files (Resource Inventory Branch 1995) rasterized to $250 \mathrm{~m}$ resolution. Forest age data were updated to the year 2002 and assumed to be indicative of forest composition over the period 1992 to 2002 when caribou population dynamics were studied. Following Apps et al. (2001) we grouped forest age into 4 age classes (Age $1=1-40$ years, Age $2=41-100$ years, Age $3=101-140$ years, Age $4>140$ years). We then estimated the area of forests $>140$ years encompassed within each distinct subpopulation range using the ArcView Geographical Information System (ESRI 1996) because of the importance of these forests as foraging habitat during winter (Rominger and Oldemeyer 1989; Rominger et al. 1996; Terry et al. 2000). We divided subpopulation size by the area of forests >140 years within each subpopulation's range to derive an index of caribou densities per area of suitable winter foraging habitat.

\section{Test of predictions}

We examined predictions of subpopulation decline by plotting subpopulation size in forest stands $>140$ years against rate of increase of each subpopulation. We determined goodness-of-fit of curves from regression analysis (Zar 1999). Statistical analyses were performed using Systat 10.2 (SYSTAT Software Inc. 2002). Results are considered significant when $\alpha<0.05$. Means are reported $\pm 1 \mathrm{SE}$ of the mean unless otherwise noted. 


\section{Results}

Rate of increase

The rate of increase was negative for 12 of the 15 subpopulations for which we were able to determine trends (Mean $=6.93 \pm 0.49$ years) (Table 2 ). The $95 \%$ confidence interval of the rate of increase in the Wells Gray subpopulation overlapped zero ( -0.1322 to 0.0233$)$, and while this corresponded with an $85 \%$ chance of decline, it was statistically indistinguishable from a stable population. Based on available information, only 1 subpopulation (Barkerville) increased significantly over the time it was monitored, while 1 subpopulation (North Cariboo Mountain) appeared stable. Trends in individual subpopulations varied from -0.1871 to 0.0496 , with smaller populations declining at the fastest rate (GLM: $R^{2}=0.510, F_{1,13}=13.555, P=0.003$ ) (Fig. 3). Rates of increase also varied with latitude with southern subpopulations generally decreasing at higher rates than northern ones (GLM: $R^{2}=0.292, \quad F_{1,13}=5.346$, $P=0.038)$.

\section{Pregnancy rates}

Pregnancy rates were determined from 134 adult female caribou in 8 subpopulations over 11 different years (Table 3). Plasma progesterone levels indicated that 123 of the 134 were pregnant. There were no apparent trends in pregnancy rates among years within subpopulations. We did not detect differences in pregnancy rates among subpopulations when data were pooled over years $(G=2.921, d f=7, P=0.892)$. The overall pregnancy rate of caribou weighted by subpopulation was $92.4 \% \pm 2.24$.

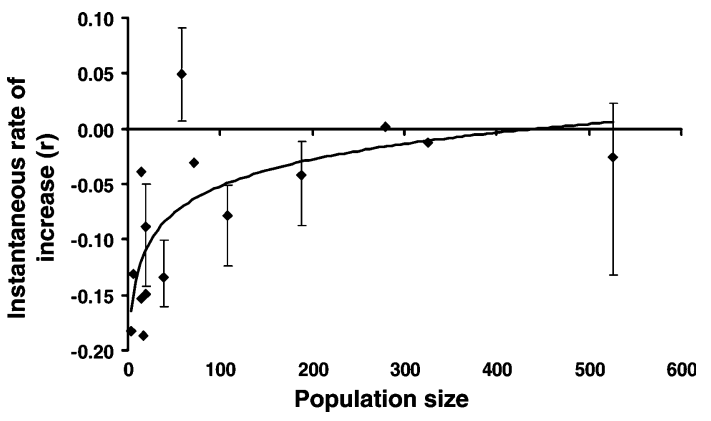

Fig. 3 Correlation between instantaneous rate of increase $(r)$ and population size in 2002 of 15 subpopulations of arboreal lichen feeding woodland caribou in British Columbia (error bars indicate $95 \%$ confidence limits based on sampling variance of population estimates when sufficient data were available; line indicates goodness-of-fit curve from regression analysis as $y=0.0349 \ln (x)$ $-0.2129)$

\section{Causes and temporal distribution of mortalities}

A total of 155 mortalities of radiocollared caribou distributed over all 15 subpopulations were recorded, 6 $(3 \mathrm{f} / 3 \mathrm{~m})$ of which were human caused. Of the 149 natural mortalities, we could confidently categorise 88 into predation, malnutrition, or accidents (Table 4). Of the 88 deaths with a known cause, 82 were females. We pooled causes of death data over sexes because the ranks of mortality causes were the same. Fifty-eight $(66 \%)$ of the known mortality causes were due to predation. Predation was the primary cause ( $\geq 50 \%$ ) of mortality in 11 of the 13 subpopulations with known causes of mortality. Apparent malnutrition was suggested for ten caribou from four subpopulations.

When adjusted for season length, we found differences in the distribution of natural mortality causes among seasons $(G=14.828, d f=4, P<0.01)$ with caribou being more likely to die during the calving and

Table 2 Subpopulation sizes $\left(N_{2002}, N_{0}\right)$ used to estimate instantaneous rate of increase $(r)$ with $95 \%$ confidence intervals, area covered by suitable forest resources ( $>140$ years) and density estimations for 15 subpopulations of arboreal lichen feeding woodland caribou in British Columbia (subpopulations ordered from south to north)

\begin{tabular}{lllllllll}
\hline Subpopulation & $N_{2002}$ & $N_{0}$ & Years & $r$ & LCI & UCI & Forest $>140$ years $\left(\mathrm{km}^{-2}\right)$ & Density $>140$ years \\
\hline Purcells-South & 17 & 63 & 7 & -0.1871 & - & - & 214 & 0.08 \\
Purcells-Central & 6 & 15 & 7 & -0.1309 & - & - & 193 & 0.03 \\
Nakusp & 108 & 173 & 6 & -0.0785 & -0.1242 & -0.0513 & 957 & 0.11 \\
Duncan & 20 & 49 & 6 & -0.1493 & - & - & 125 & 0.16 \\
Columbia-South & 39 & 114 & 8 & -0.1341 & -0.1608 & -0.1009 & 562 & 0.07 \\
Frisby-Boulder & 20 & 34 & 6 & -0.0884 & -0.1424 & -0.0500 & 265 & 0.08 \\
Columbia-North & 188 & 232 & 5 & -0.0421 & -0.0876 & -0.0113 & 1952 & 0.10 \\
Kinbasket-South & 14 & 17 & 5 & -0.0388 & - & - & 193 & 0.07 \\
Groundhog & 15 & 44 & 7 & -0.1537 & - & - & 435 & 0.03 \\
Wells Gray & 526 & 628 & 7 & -0.0253 & -0.1322 & 0.0233 & 3587 & 0.15 \\
Barkerville & 58 & 39 & 8 & 0.0496 & 0.0063 & 0.0914 & 543 & 0.11 \\
North Cariboo Mountain & 279 & 274 & 9 & 0.0020 & - & - & 775 & 0.36 \\
George Mountain & 4 & 25 & 10 & -0.1833 & - & - & 95 & 0.04 \\
Narrow Lake & 72 & 79 & 3 & -0.0309 & - & - & 287 & 0.25 \\
Hart Ranges & 325 & 370 & 10 & -0.0130 & - & - & 1948 & 0.17 \\
\hline
\end{tabular}

LCI lower confidence interval, $U C I$ upper confidence interval 
Table 3 Pregnancy rates (animal sample) of 134 adult female arboreal lichen feeding woodland caribou ( $>2.5$ years) in British Columbia between 1984-1997, determined from serum progesterone levels

\begin{tabular}{|c|c|c|c|c|c|c|c|c|}
\hline Year & Purcells-South & Purcells-Central & Duncan & Columbia-South & Columbia-North & Kinbasket-South & Wells Gray & Barkerville \\
\hline 1984 & & & & & & & $1.00(12 / 12)$ & \\
\hline 1985 & & & & & & & $1.00(6 / 6)$ & \\
\hline 1986 & & & & & & & $0.89(24 / 27)$ & \\
\hline 1987 & & & & & & & $1.00(4 / 4)$ & \\
\hline 1988 & & & & & & & $1.00(1 / 1)$ & \\
\hline 1992 & & & $1.00(2 / 2)$ & $0.88(7 / 8)$ & $1.00(2 / 2)$ & $1.00(2 / 2)$ & & \\
\hline 1993 & & & & $1.00(3 / 3)$ & $0.88(7 / 8)$ & & $0.86(12 / 14)$ & $1.00(3 / 3)$ \\
\hline 1994 & $1.00(4 / 4)$ & $1.00(3 / 3)$ & & & & & $1.00(4 / 4)$ & \\
\hline 1995 & & & & & & & $1.00(4 / 4)$ & \\
\hline 1996 & & & & & & & $1.00(5 / 5)$ & $1.00(1 / 1)$ \\
\hline 1997 & $0.75(3 / 4)$ & $0.67(2 / 3)$ & & & $0.75(3 / 4)$ & $1.00(1 / 1)$ & $1.00(6 / 6)$ & $0.67(2 / 3)$ \\
\hline Mean \pm SE & $0.88 \pm 0.13$ & $0.84 \pm 0.17$ & $1.00 \pm 0$ & $0.94 \pm 0.06$ & $0.88 \pm 0.07$ & $1.00 \pm 0$ & $0.98 \pm 0.02$ & $0.89 \pm 0.11$ \\
\hline
\end{tabular}

Table 4 Cause of mortality and proportion of mortalities with known cause killed by predators of arboreal lichen feeding woodland caribou in British Columbia (number in brackets indicates males)

\begin{tabular}{llllll}
\hline Subpopulation & Accident & Malnutrition & Predation & Proportion predation & Unknown \\
\hline Purcells-South & - & - & $9(1)$ & 1.00 & 3 \\
Purcells-Central & 1 & - & - & 0 & 1 \\
Nakusp & 1 & - & $4(1)$ & 0.80 & $6(1)$ \\
Duncan & - & $1(1)$ & 2 & 0.67 & - \\
Columbia-South & $4(1)$ & - & 5 & 0.56 & 4 \\
Frisby-Boulder & 1 & - & - & 0 & 7 \\
Columbia-North & 5 & 2 & $9(1)$ & 0.56 & 1 \\
Kinbasket-South & - & - & - & - & 4 \\
Groundhog & - & - & 2 & 1.00 & $27(1)$ \\
Wells Gray & 7 & 6 & 22 & 0.63 & 2 \\
Barkerville & 1 & - & 2 & 0.67 & 1 \\
North Cariboo Mountain & - & - & 1 & 1.00 & 1 \\
George Mountain & - & - & $1(1)$ & 1.00 & $3(2)$ \\
Narrow Lake & - & - & - & - & 61 \\
Hart Ranges & - & 1 & 1 & 0.50 & \\
Total & 20 & 10 & 58 & 0.66 & \\
\hline
\end{tabular}

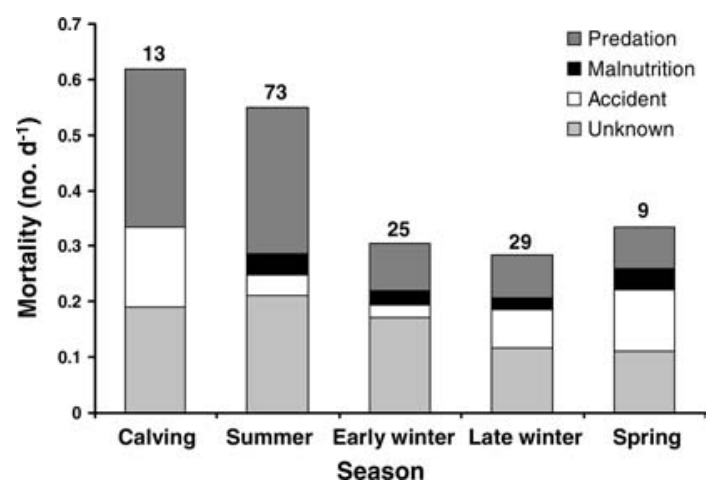

Fig. 4 Number of natural mortalities per day of arboreal lichen feeding woodland caribou (pooled females and males) in British Columbia by season (calving, summer, early winter, late winter, spring) from 1984-2002. Causes of death were predation (dark grey square), malnutrition (light grey square), accident (open square) and unknown (light grey square). Data adjusted for seasonal length (days): calving (21 May-10 June), summer (11 June-21 October), early winter (22 October-11 January), late winter (12 January-23 April) and spring (24 April-20 May). Labels above the bars indicate total number of naturally-caused mortalities summer season (Fig. 4). Caribou are also more likely to die due to predation during calving and summer than during other seasons $(G=19.303, \quad d f=4$, $P<0.001)$.

\section{Population densities relative to habitat index}

The instantaneous rate of increase declined faster with decreasing caribou densities per area of suitable habitat (GLM: $R^{2}=0.388, F_{1,13}=8.231, P=0.013$ ) (Fig. 5). On the basis of information available (shape of the goodness-of-fit curve from the regression analysis) there is no evidence that, over the entire distribution of these caribou, the rate of decline is decelerating at very low densities.

\section{Discussion}

The principal objective of our study was to differentiate between the three hypotheses (food, predation-sensitive foraging (PSF) and predation) of causes for the popu- 


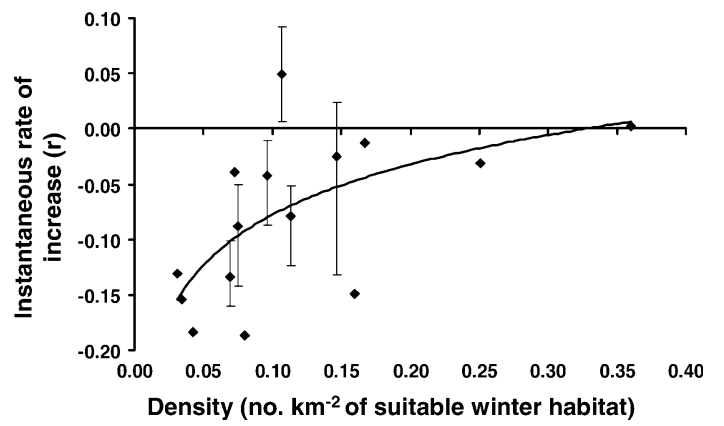

Fig. 5 Correlation between instantaneous rate of increase $(r)$ and density of caribou per area of suitable winter foraging habitat (area of forest older than 140 years) of 15 subpopulations of arboreal lichen feeding woodland caribou in British Columbia (error bars indicate $95 \%$ confidence limits based on the sampling variance of population estimates when sufficient data were available; the line indicates the goodness-of-fit curve from regression analysis as $y=0.0655 \ln (x)+0.0731)$

lation decline of arboreal lichen feeding woodland caribou in British Columbia. The food hypothesis predicted that the decline of these caribou is due to increased intraspecific competition for food as a consequence of loss of mature lichen bearing forests by logging. Consequently, we predicted that the highest rates of increase would occur at low population densities per area of suitable winter foraging habitat, that pregnancy rates would be lower at high population densities, that malnutrition would be the primary cause of mortality and that mortality would predominantly occur during winter when foods should be most limited. The PSF hypothesis proposed that resource restriction and predation interact such that as food supply decreases, caribou increase their risk of predation due to more time spent foraging in riskier habitat. Thus, we predicted that the highest rates of increase would occur at low population densities of suitable winter foraging habitat, that pregnancy rates would be lower at high population densities, but that predation would be the primary mortality cause and most would occur during winter when foods should be most limited. The predation hypothesis proposed that predators will cause caribou extirpation when they are a secondary prey and predators depend on some other primary prey. To support this hypothesis, we predicted that the highest rates of increase would occur at high population densities per area of suitable winter foraging habitat, that pregnancy rates would be high, that predation would be the primary cause of mortality and mortality would predominantly occur during summer when caribou overlap with both alternate prey and their predators.

Our results support the predictions of the predation hypothesis. First, we found negative rates of increase even at very low caribou density. The increasingly negative rate of increase continued even when caribou densities were very low suggesting a lack of refuge effect at low numbers. Second, pregnancy rates were high and did not differ among subpopulations (and thus with population density). Third, predation was the primary $(\geq 50 \%)$ cause of mortality in 11 of 13 subpopulations of arboreal lichen feeding woodland caribou in British Columbia with known causes of mortality. Finally, caribou were more likely to die during the summer, when food was more abundant, than during other seasons.

Theoretical studies have suggested that inverse density dependence or Allee effects can have dramatic impacts on the dynamics of small populations (e.g. Lande et al. 1994; Dennis 2002; Fowler and Ruxton 2002). The primary consequence of inverse density dependence is an increase in the extinction risk when populations fall below a critical density threshold (Dennis 2002). Although inverse density dependence has been described across many taxa including mammals, empirical evidence remains rare (Sæther et al. 1996; Courchamp et al. 1999a) because of difficulties in measuring population growth rates at low densities (Morris 2002). Our results provide empirical evidence of an inverse density-dependent decline or Allee effect in a large herbivore.

Several mechanisms have been hypothesized to cause inverse density dependence. Most studies have focused on intraspecific inverse density dependence as mediated by social interactions among conspecifics, including increased efficiency of mating with higher density (e.g. Kuussaari et al. 1998) and increased efficiency of cooperative behaviours with density (e.g. Clutton-Brock et al. 1998; Courchamp et al. 1999b; 2000). Conversely, inverse density dependence as mediated by complex interspecific relationships involving more than two species, such as predator-prey interactions, have seldom been considered (Courchamp et al. 1999a). Sinclair et al. (1998) provided empirical evidence of inverse density dependence from altered predator-prey systems in Australia, where an introduced predator species (red fox, Vulpes vulpes) drove a remnant population of small marsupial (eastern barred bandicoot, Perameles gunnii) to extinction. The extinction was a consequence of depensatory predation on secondary prey resulting in increased per capita mortality at low population densities.

Our results provide evidence of inverse density dependence as a consequence of high mortality rates caused by predation in a large herbivore in a multi-prey, multi-predator system with a full complement of five natural predators (excluding humans). Wolves, cougars and the two species of bears have all been identified as major predators of arboreal lichen feeding woodland caribou while predation by wolverine was rare (Wittmer 2004). Wolf predation occurred primarily in northern subpopulations and cougar predation occurred primarily in southern subpopulations. In contrast, bear mortality occurred at approximately equal rates across the distribution of caribou. The inverse density-dependent decline we observe, however, is unlikely a consequence of predator-prey interactions where caribou remain a primary prey even at very low prey densities (i.e. type II functional response). At the low caribou densities in this study wolves and cougars would spend little time ac- 
tively searching for or handling caribou compared to the other more abundant species, and thus predation on caribou would be largely incidental. In addition, bears in the range of arboreal lichen feeding woodland caribou are mostly herbivorous (Hobson et al. 2000) and thus unlikely to show a numerical or functional response to very small populations of caribou.

We suggest that two other factors may contribute to the rapid decline of the small subpopulations compared to the larger subpopulations. The first potential factor is because arboreal lichen feeding woodland caribou live in groups and group sizes in very small populations are likely smaller than group sizes in larger populations. If a predator kills one caribou when it encounters a group, then the predation rate on smaller populations with smaller groups would be higher provided group encounter rates were independent of group size. The second factor that may have caused the smaller subpopulations to decline more rapidly than the larger subpopulations is that the number of prey and predators were unlikely consistent across the range of all caribou subpopulations. In particular, we detected a significant relationship between the rate of increase and latitude. Small caribou populations with very low rates of increase were more common in southern areas that may have a greater abundance of younger forests and thus larger populations of alternate ungulate species and their predators.

It is also possible that the lower rates of increase of the smaller, generally more southern subpopulations were also due to differences in juvenile recruitment resulting from environmental variability, as has been proposed by Sæther (1997) and Gaillard et al. (1998; 2000) in some other species. However, because pregnancy rates were high across the study area and mortality was primarily caused by predators during calving and summer, and mortality rates were higher in the smaller populations (Wittmer 2004), the effect of juvenile recruitment resulting from environmental variability on the variation in rate of increase is likely minor.

The continued high rate of decline at low densities has important implications for the population dynamics of woodland caribou over their entire distribution in North America. Predation is generally considered the proximate factor limiting woodland caribou across most of their distribution (Bergerud and Elliot 1986; Bergerud 1996; Stuart-Smith et al. 1997; Rettie and Messier 1998; Schaefer et al. 1999). It has been hypothesized that predation might be facilitated by logging and other changes to caribou habitat that favour early seral stage forest (Rettie and Messier 1998). These young forest stands are thought to support higher densities of alternate prey species, primarily moose, that in turn support higher predator densities leading to increased predation on caribou (Bergerud and Elliot 1986; Seip 1992). Our results suggest that the loss of mature forests has not yet had a significant effect on caribou populations by increasing intraspecific competition for winter food (i.e. arboreal lichen) but that it may compromise the predator avoidance strategy of caribou where they fail to separate themselves from increasing alternate prey populations and their predators. Their failure to reduce predation risk exposes caribou to an increasing predator population that has a numerical response to their primary prey. Our results suggest that the decline of woodland caribou in the absence of resource competition is due to apparent competition where caribou may become secondary prey resulting in populations declining towards extinction due to high predation rates. Thus, recovery of woodland caribou will require a multispecies perspective and an appreciation for the influence of inverse density dependence on caribou population trajectories.

Acknowledgements This project was funded by the British Columbia Ministries of Forests and Environment, Columbia Basin Fish and Wildlife Compensation Program, Parks Canada, Forest Renewal British Columbia, and numerous forestry companies that operate across the range of arboreal lichen feeding woodland caribou. H.U. Wittmer was supported by fellowships from the International Council for Canadian Studies, the University of British Columbia, and the Faculty of Agricultural Sciences at the University of British Columbia. We are thankful to the numerous people involved in data collection. C. Apps provided access to GIS basemaps and B. Lessard engaged in many stimulating discussions. P. Arcese, J. Brashares, F. Courchamp, M. Festa-Bianchet and D. Shackleton provided many helpful comments on earlier versions of this manuscript. Finally, we thank an anonymous reviewer whose comments greatly improved this manuscript.

\section{References}

Allee WC, Park O, Emerson AE, Part T, Schmidt KP (1949) Principles of animal ecology. Saunders, Philadelphia

Apps CD, McLellan BN, Kinley TA, Flaa JP (2001) Scale-dependent habitat selection by mountain caribou, Columbia Mountains, British Columbia. J Wildl Manage 65:65-77

Arditi R, Ginzburg LR (1989) Coupling in predator prey dynamics - ratio-dependence. J Theor Biol 139:311-326

Bartmann RM, White GC, Carpenter LH, Garrott RA (1987) Aerial mark-recapture estimates of confined mule deer in pinyon-juniper woodland. J Wildl Manage 51:41-46

Bergerud AT (1974) Decline of caribou in North America following settlement. J Wildl Manage 38:757-770

Bergerud AT (1996) Evolving perspectives on caribou population dynamics, have we got it right yet? Rangifer Spec Issue 9:95116

Bergerud AT, Elliot JP (1986) Dynamics of caribou and wolves in northern British Columbia. Can J Zool 64:1515-1519

Bergerud AT, Page RE (1987) Displacement and dispersion of parturient caribou at calving as an antipredator tactic. Can $\mathbf{J}$ Zool 65:1597-1606

Bjørnstad ON, Grenfell BT (2001) Noisy clockwork: time-series analysis of population fluctuations in animals. Science 293:638 643

Caughley G (1976) Wildlife management and the dynamics of ungulate populations. In: Coaker TH (ed) Applied biology, vol 1. Academic, London, pp 183-246

Caughley G (1994) Directions in conservation biology. J Anim Ecol 63:214-244

Caughley G, Sinclair ARE (1994) Wildlife ecology and management. Blackwell Scientific, Oxford 
Clutton-Brock TH, Gaynor D, Kansky R, MacColl ADC, McIlrath G, Chadwick P, Brotherton PNM, O'Riain JM, Manser M, Skinner JD (1998) Cost of cooperative behaviour in suricates (Suricata suricatta). Proc R Soc Lond B 265:185190

COSEWIC (2002) COSEWIC assessment and update status report on the woodland caribou Rangifer tarandus caribou in Canada. Committee on the Status of Endangered Wildlife in Canada, Ottawa

Coulson T, Catchpole EA, Albon SD, Morgan BJT, Pemberton JM, Clutton-Brock TH, Crawley MJ, Grenfell BT (2001) Age, sex, density, winter weather, and population crashes in Soay sheep. Science 292:1528-1531

Courchamp F, Clutton-Brock T, Grenfell B (1999a) Inverse density-dependence and the Allee effect. Trends Ecol Evol 14:405410

Courchamp F, Grenfell B, Clutton-Brock T (1999b) Population dynamics of obligate cooperators. Proc R Soc Lond B 266:557563

Courchamp F, Clutton-Brock T, Grenfell B (2000) Multipack dynamics and the Allee effect in the African wild dog, Lyacon pictus. Anim Conserv 3:277-285

Dennis B (2002) Allee effects in stochastic populations. Oikos 96:389-401

ESRI (1996) Arc View GIS. Environmental Systems Research Institute Inc., Redlands

Fowler MS, Ruxton GD (2002) Population dynamic consequences of Allee effects. J Theor Biol 215:39-46

Gaillard J-M, Festa-Bianchet M, Yoccoz NG (1998) Population dynamics of large herbivores: variable recruitment with constant adult survival. Trends Ecol Evol 13:58-63

Gaillard J-M, Festa-Bianchet M, Yoccoz NG, Loison A, Toïgo C (2000) Temporal variation in fitness components and population dynamics of large herbivores. A Rev Ecol Syst 31:367-393

Hayes RD, Gunson JR (1995) Status and management of wolves in Canada. In: Carbyn LN, Fritts SH, Seip DR (eds) Ecology and conservation of wolves in a changing world. Canadian Circumpolar Institute, Occasional Publication No. 35, Edmonton, Alberta, pp 21-33

Hobson KA, McLellan BN, Woods JG (2000) Using stable carbon (delta C-13) and nitrogen (delta N-15) isotopes to infer trophic relationships among black and grizzly bears in the upper Columbia River basin, British Columbia. Can J Zool 78:13321339

Holt RD (1977) Predation, apparent competition and the structure of prey communities. Theor Popul Biol 12:197-229

Holt RD (1984) Spatial heterogeneity, indirect interactions, and the coexistence of prey species. Am Nat 124:377-406

Holt RD, Lawton JH (1994) The ecological consequences of shared natural enemies. A Rev Ecol Syst 25:495-520

Kuussaari M, Saccheri I, Camara M, Hanski I (1998) Allee effect and population dynamics in the Glanville fritillary butterfly. Oikos 82:384-392

Lande R, Engen S, Sæther B-E (1994) Optimal harvesting, economic discounting and extinction risk in fluctuating populations. Nature 372:88-90

Mduma SAR, Sinclair ARE, Hilborn R (1999) Food regulates the Serengeti wildebeest: a 40-year record. J Anim Ecol 68:11011122

Meidinger DV, Pojar J (1991) Ecosystems of British Columbia. British Columbia Ministry of Forests, Special Report Series 4, Victoria, British Columbia

Milner JM, Elston DA, Albon SD (1999) Estimating the contributions of population density and climatic fluctuations to interannual variation in survival of Soay sheep. J Anim Ecol 68:1235-1247

Morris DW (2002) Measuring the Allee effect: positive density dependence in small mammals. Ecology 83:14-20

Post E, Stenseth NC (1998) Large-scale climatic fluctuation and population dynamics of moose and white-tailed deer. J Anim Ecol 67:537-543
Rempel RS, Elkie PC, Rodgers AR, Gluck MJ (1997) Timbermanagement and natural-disturbance effects on moose habitat: landscape evaluation. J Wildl Manage 61:517-524

Resource Inventory Branch (1995) Relational data dictionary (RDD) 2.0. British Columbia Ministry of Forests, Victoria

Rettie WJ, Messier F (1998) Dynamics of woodland caribou populations at the southern limit of their range in Saskatchewan. Can J Zool 76:251-259

Roemer GW, Donlan CJ, Courchamp F (2002) Golden eagles, feral pigs, and insular carnivores: how exotic species turn native predators into prey. Proc Natl Acad Sci USA 99:791-796

Rominger EM, Oldemeyer JL (1989) Early-winter habitat of woodland caribou, Selkirk Mountains, British Columbia. J Wildl Manage 60:719-728

Rominger EM, Robins CT, Evans MA (1996) Winter foraging ecology of woodland caribou in northeastern Washington. J Wildl Manage 60:719-728

Ropstad E, Johansen O, King C, Dahl E, Albon SD, Langvatn RL, Irvine RJ, Halvorsen O, Sasser G (1999) Comparison of plasma progesterone, transrectal ultrasound and pregnancy specific proteins (PSPB) used for pregnancy diagnosis in reindeer. Act Vet Scand 40:151-162

Sæther B-E (1997) Environmental stochasticity and population dynamics of large herbivores: a search for mechanisms. Trends Ecol Evol 12:143-149

Sæther B-E, Ringsby TH, Roskaft E (1996) Life history variation, population processes and priorities in species conservation: towards a reunion of research paradigms. Oikos 77:217-226

Schaefer JA, Veitch AM, Harrington FH, Brown WK, Theberge JB, Luttich SN (1999) Demography of decline of the Red Wine Mountains caribou herd. J Wildl Manage 63:580-587

Seip DR (1992) Factors limiting woodland caribou populations and their interrelationships with wolves and moose in southeastern British Columbia. Can J Zool 70:1494-1503

Shackleton D (1999) Hoofed mammals of British Columbia. Royal British Columbia Museum and University of British Columbia Press, Vancouver

Shenk TM, White GC, Burnham KP (1998) Sampling-variance effects on detecting density dependence from temporal trends in natural populations. Ecol Monogr 68:445-463

Sibly RM, Hone J (2002) Population growth rates and its determinants: an overview. Phil Trans R Soc Lond B 357:1153-1170

Sinclair ARE (1989) Population regulation in animals. In: Cherrett JM (ed) Ecological concepts. Blackwell Scientific, Oxford, pp 197-241

Sinclair ARE (1991) Science and the practice of wildlife management. J Wildl Manage 55:767-773

Sinclair ARE, Arcese P (1995) Population consequences of predation-sensitive foraging: the Serengeti wildebeest. Ecology 76:882-891

Sinclair ARE, Krebs CJ (2002) Complex numerical responses to top-down and bottom-up processes in vertebrate populations. Phil Trans R Soc Lond B 357:1221-1231

Sinclair ARE, Pech RP, Dickman CR, Hik D, Mahon P, Newsome AE (1998) Predicting effects of predation on conservation of endangered prey. Conserv Biol 12:564-575

Spalding DJ (1990) The early history of moose (Alces alces): distribution and relative abundance in British Columbia. Contr. to Nat. Sci. \#11. Royal B.C. Museum Victoria, British Columbia

Stephens PA, Sutherland WJ (1999) Consequences of the Allee effect for behaviour, ecology and conservation. Trends Ecol Evol 14:39-42

Stuart-Smith AK, Bradshaw CJA, Boutin S, Herbert DM, Rippin AB (1997) Woodland caribou relative to landscape patterns in northeastern Alberta. J Wildl Manage 61:622-633

Sutherland WJ (1996) Predicting the consequences of habitat loss for migratory populations. Proc R Soc Lond B 263:1325-1327

Sutherland WJ, Norris K (2002) Behavioural models of population growth rates: implications for conservation and prediction. Phil Trans R Soc Lond B 357:1273-1284

Systat Software Inc (2002) SYSTAT 10.2-Statistics I. Systat Software Inc., Richmond 
Terry EL, McLellan BN, Watts GS (2000) Winter habitat ecology of mountain caribou in relation to forest management. J Appl Ecol 37:589-602

White GC (1996) Program NOREMARK software reference manual. Available online. http://www.cnr.colostate.edu/class_info/fw663/noremark.pdf. Cited 15 July 2004
Wittmer HU (2004) Mechanisms underlying the decline of mountain caribou (Rangifer tarandus caribou) in British Columbia. Ph.D. Dissertation, University of British Columbia

Zar JH (1999) Biostatistical analysis, 4th edn. Prentice Hall, Upper Saddle River 